NASA/TM-2001-210373

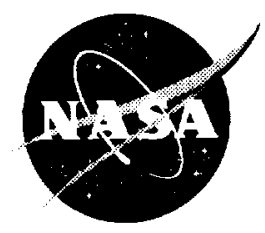

\title{
Near-Net Shape Powder Metallurgy Rhenium Thruster
}

Todd Leonhardt, Mark Hamister, and Jan C. Carlén

Rhenium Alloys, Inc., Elyria, Ohio

James Biaglow and Brian Reed

Glenn Research Center, Cleveland, Ohio

Prepared for the

36th Joint Propulsion Conference

cosponsored by the AIAA, ASME, SAE, and ASEE

Huntsville, Alabama, July 17-19, 2000

National Aeronautics and

Space Administration

Glenn Research Center 


\section{Acknowledgments}

The authors would like to acknowledge James Downs for his dedication and significant contribution to the development of the NNS processing techniques, Nancy Moore for her technical assistance with the program and in preparing this publication, Edwin Lipowski, Pat Hamilton, and Jack Schafer for their technical assistance and the NASA On Board Space Propulsion Branch and the SBIR office for their technical and financial support.

Trade names or manufacturers' names are used in this report for identification only. This usage does not constitute an official endorsement, either expressed or implied, by the National Aeronautics and Space Administration.

Available from

NASA Center for Aerospace Information

7121 Standard Drive

Hanover, MD 21076

Price Code: A03
National Technical Information Service 5285 Port Royal Road Springfield, VA 22100 Price Code: $\mathrm{A} 03$ 


\title{
NEAR-NET SHAPE POWDER METALLURGY RHENIUM THRUSTER
}

\author{
Todd Leonhardt, Mark Hamister, and Jan C. Carlén \\ Rhenium Alloys, Inc. \\ Elyria, Ohio \\ James Biaglow and Brian Reed \\ National Aeronautics and Space Administration \\ Glenn Research Center \\ Cleveland, Ohio
}

\begin{abstract}
This paper describes the development of a method to produce a near-net shape (NNS) powder metallurgy (PM) rhenium combustion chamber of the size $445 \mathrm{~N}$ (100 lbf) used in a high performance liquid apogee engine. These engines are used in low earth orbit and geostationary orbit for satellite positioning systems. A research program was established which was funded under a NASA Phase 1 and II SBIR. The goal was to establish an alternative manufacturing method for the production of powder metallurgy rhenium combustion chambers. The task to reduce the quantity of rhenium required to produce rhenium chambers was undertaken to lower the cost of the chambers. This paper will focus on the evolution of manufacturing techniques for rhenium thruster chambers. Several manufacturing methods used to produce a near-net shape rhenium chamber are discussed, including the research and development work needed to proceed from cylindrical, sintered, hot isostatic pressed (HIPed) rhenium ingots through the manufacturing of rhenium tubes and eventually to make a complex near-net shape rhenium chamber. Several breakthroughs in processing were achieved during this research study. There were improvements in the design of the mandrel, fixturing of the mandrel in cold isostatic pressing (CIP) latex molds, altering wet-bag CIP parameters to achieve the complex shape, thermal processing for controlling shape and properties, containerless HIPing, and the reduction of machining steps. One of the major breakthroughs was the two-part mandrel with a complex shape for CIP processing which enabled the compaction of rhenium metal powder. Another important innovation was hot isostatic pressing (HIPing) without a canning material around the chamber. This innovation had a major impact on the surface finish and cost of the chambers. A study of spin forming was undertaken to try to obtain rolled thenium mechanical properties on a NNS rhenium thruster. The spin forming method
\end{abstract}

alters the HIPed rhenium microstructure to a rolled rhenium structure while decreasing wall thickness of the NNS thruster to close to final dimensions. The developments in near-net shape powder metallurgy rhenium combustion chambers reported in this paper will reduce manufacturing cost of the rhenium chambers by $25 \%$, and reduce the manufacturing time by 30 to $40 \%$. The quantity of rhenium metal powder used to produce a rhenium chamber is reduced by approximately $70 \%$ and the subsequent reduction in machining schedule and costs is nearly $50 \%$. The overall savings provided by the production of nearnet shape powder metallurgy rhenium chambers will become an important benefit when increase of performance, reliability, and cost reduction will be required to compete in the international market for satellite propulsion components.

\section{Introduction}

The use of powder metallurgy (PM) rhenium as a material for high performance liquid apogee engines has shown to be an excellent material for this high temperature application. ${ }^{1: 2}$ Rhenium has a melting point of $3459 \mathrm{~K}$ and has the highest modulus of elasticity of all refractory metals. PM rhenium has shown consistent high yield and ultimate strengths at ambient and elevated temperature as illustrated in Table $1 .^{3}$ Also, PM rhenium has excellent creep and low cycle fatigue properties.

The first powder metallurgy apogee thrusters were produced from several different sizes of PM rhenium ingots. The ingots were produced by cold isostatic pressing (CIP) 15-30 kilogram of rhenium metal powder in a large diameter CIP mold placed in a retaining can. The mold and can were lowered into a CIP vessel and immersed in water, figure 1 . The wet bag process uses hydrostatic pressures of 210 to 410 MPa to apply the pressure to the mold. ${ }^{+}$The isostatic pressure on the mold transfers the load to the rhenium 
powder, which consolidates the powder into a green compact. The large ingots as consolidated powder were removed from the mold and placed into molybdenum boats with a layer of alumina granules to support the ingots and keep them separated from the boat. The ingots were pre-sintered for the purpose of decreasing the oxygen content and increasing green strength, so the ingots could be easily handled. ${ }^{4.5}$ The rhenium ingots were sintered at .8 of the melting point, which was required to produce a dense rhenium component. The sintering process was performed in a hydrogen atmosphere or in vacuum for several hours. A long duration of time at temperature was necessary to achieve a sintered density around 90 to $95 \%$ of the theoretical density $(21.04 \mathrm{~g} / \mathrm{cc})$. After the sintering operation, the ingots were encapsulated in a metal can in an operation called canning. The metal cans were evacuated to a very high vacuum and sealed. This process insures that argon will not permeate the ingots during the hot isostatic pressing (HIPing). Hot isostatic pressing was performed at high temperatures and pressures for several hours. The ingots would have a density greater than $97 \%$ of theoretical density.

For the TRW and Kaiser Marquart $100 \mathrm{lb}$ force thrusters, two ingots were required as shown in figures 2 and 3 . The small diameter ingots were for the barrel sections and the larger diameter ingot were for the exit cones. To produce the thrusters, extensive machining was employed by electric discharge machining (EDM) and diamond grinding of the ingots. The EDM was used for all rough material removal. The inside diameter had to be EDM plunged to produce a starter hole for wire EDM. This process was employed to produce the inside diameter of the thruster figure 4 . Then diamond grinding was performed in two steps. The first was a rough diamond grinding and the second was a slower final diamond grinding to final inside dimensions, figure 5 . After the inside diameter was completed, the outside diameter was EDM cut to remove material that establishes the contours of the thruster. Then diamond grinding was used to obtain final size as shown in figure 6. As seen in figure 7 , the ingot process produces a significant amount of rhenium scrap.

The barrel section and exit cone were electron beam (EB) welded together. The electron beam weld produced a limited heat affected zone (HAZ) and excellent penetration, figure 8 . The final step after welding was a limited diamond grinding to remove any surface changes due to welding. In recent years the TRW $100 \mathrm{lbf}$ thruster has been produced using only one ingot, but the Kaiser Marquart 100lbf thruster was made via two-part construction, figure 9. The time required to produce one chamber via the ingot method was 16 to 18 weeks.

\section{Research lnitiative Phase I}

The desire to reduce the manufacturing cost and time required to manufacture a rhenium thruster was of great interest to NASA Glenn Research Center and the Small Business Innovation Research (SBIR) Office. They sponsored a phase I SBIR to find an alternate method of manufacturing rhenium thrusters by powder metallurgy method. The literature and several publications, references 1-3, indicate that powder metallurgy rhenium has excellent mechanical properties and a uniform and reproducible microstructure. The characteristics of powder metallurgy rhenium make it a more consistent product than other forms of rhenium. Under the phase I SBIR, the goal was to produce a small diameter $25 \mathrm{lbf}$. rhenium thruster. To achieve the goal several kilograms of rhenium metal powder were used to produce small diameter rhenium tubes. The rhenium powder was placed in a mold with a steel mandrel and CIPed to the shape of a tube. The mandrel was removed from the green compact tube. The tubes were pre-sintered and then sintered to high relative density. Several techniques were investigated on mold and closure design. Sintered and sintered HIPed tubes were cold worked via spin forming to produce a complex shape.

Spin forming was investigated to cold work rhenium to a complex shape by reducing the outside diameter and forming the tube. During spin forming, a mandrel is placed inside the tube for support and to prevent the inside diameter from tlexing due to compressive loading, figure 10 . The spin forming process uses a single point tool under high force and rotation to move the rhenium tube to the specified dimensions and to increase density. Spin forming simulates the microstructure and properties of cold rolled thenium. After spin forming, the tube was annealed to recrystallize the worked areas and reduce the hardness. Several small diameter rhenium tubes were spun down to near final dimensions, but due to the high degree of deformation, cracks appeared in the surface of the tube, figure 11. The spin forming process could not control the deformation on the single point tool, so the reduction in wall varied from 5 to $20 \%$. Typically rhenium is only reduced by 10 to $12 \%$ of the wall thickness per pass, this is due to deformation hardening that occurs during mechanical working. Spin forming showed great promise of 
reducing cost and time of manufacturing, and provided excellent mechanical properties. Based on the experimentation, Rhenium Alloys, Inc. was awarded a phase II SBIR.

\section{Research Initiative Phase II}

In the phase II, the goal was to manufacture two differently designed $100 \mathrm{lb}(440 \mathrm{~N}$ and $490 \mathrm{~N})$ high performance bipropellant liquid apogee rhenium iridium thrusters. The manufacturing process was to spin form large diameter tubes to the TRW $440 \mathrm{~N}$ thruster and Kaiser Marquardt $490 \mathrm{~N}$ thruster specifications. Both thrusters use rhenium as the substrate and iridium as an oxidation resistant coating. The first major hurdle was to produce large diameter tubes. The production of the tubes was made via cold isostatic pressing (CIP) rhenium metal powder in a CIP mold with a large diameter steel mandrel. This process of pressing with a hard mandrel is called the collapsing bag technique. The rhenium tubes were removed from the mold and the mandrel was removed from the green rhenium compact tube. A limited pre-sinter was performed and the tube was placed vertically in a sintering furnace and sintered for several hours. The sintered density was 90 to $92 \%$ of the theoretical density. To increase the density to greater than $97 \%$, HIPing was employed, but because the tube is a complex shape, the canning operation is prohibitive. To form a metal can around a complex shape would have been extremely difficult and be very costly. Containerless hot isostatic pressing (HIP) of high-density sintered components was developed to produce a near fully dense rhenium large diameter tube, figure 12. This development allowed HIPing to be performed without a can, and to achieve very high densities. Spin forming was employed to make the tubes concentric and to form a complex shape. This was done with several light spin forming passes, figure 13. After as little as $10 \%$ cold working, rhenium must be thermally processed. ${ }^{5}$ Rhenium work hardens faster than all other pure metals. ${ }^{5}$ During sequential processing of spinning the tube into a thruster, cracks developed from what appeared to be over-worked rhenium metal, figure 14 . The microstructure of the inside and outside diameters had fine recrystallized grains, figure 15 . The center of the tube wall had very large grains, figure 16 , and a hardness differential was seen from center to edge. The problem with spin forming rhenium was uncven work, controlling the degree of deformation, and supporting the inside diameter of the tube. Due to these problems the spinforming process was abandoned as a suitable method to produces the rhenium $100 \mathrm{lbf}$ chambers.

\section{Alternate Method of Fabrication}

Spin forming rhenium failed to produce a reproducible process to manufacture rhenium thrusters. All large diameter tubes that received a sequence of spin forming and annealing failed before reaching the specified dimensions. The production of large diameter tubes showed possibilities. so modifying the process should be successful. The TRW $440 \mathrm{~N}$ thruster has a large barrel section and a smaller exit cone versus the Kaiser Marquardt $490 \mathrm{~N}$ thruster, which has a smaller barrel, and a large exit cone. Because the TRW chamber was considered to be less complex in shape, it was the first chamber selected to develop a complex shape tube via the CIP process. Instead of spinning a simple tube to a complex shape, the goal was to CIP a complex, near net shape tube. This manufacturing method employed a two-part mandrel, which separates at the narrowest point of the chamber. This was done so the mandrel would separate from the green compact easily. The mandrel would hold the contour of the inside diameter of the thruster and maintain specific dimensional tolerances, figure 17. Since the mold is flexible, the complex shaped mandrel produced a near net shape (NNS) part with contoured inside and outside surfaces, ${ }^{4}$ figure 18 . The complex mandrel is removed before the green NNS compact is lightly pre-sintered, and then pre-sintered again at a higher temperature to promote shrinkage before final sintering. figure 19. The pressed and pre-sintered densities are very high, because of the thin wall of the NNS thruster, The sintered density ranged from 95 to $98 \%$ of theoretical density. The NNS thruster is close to the desired dimensions as sintered, figure 20 , and during HIPing the NNS thruster shrinks an additional 2 to $4 \%$, which guarantees that dimensional tolerance is reached. The wall thickness was $7.6 \mathrm{~mm}$, which prevented slump during sintering. The first near net shaped chamber produced via the CIPing and complex mandrel was a TRW $100 \mathrm{lbf}$ $(440 \mathrm{~N})$ thruster with a density of $99.9 \%$. The mandrel was too large so after shrinking, the first chamber was over-sized on the inside diameter by $1.5 \mathrm{~mm}$ at the throat and a part of the exit cone cracked. Sequential trials of NNS processing were more successful in obtaining a full size chamber with good dimensional tolerance controls. Predicting the shrinkage rates and understanding the consolidation process was of great importance. Now it was possible to predict for a given chamber, the shrinkage rate and the dimensions of the mandrel. The TRW $440 \mathrm{~N}$ thruster was delivered to NASA after machining, figure 21 . The TRW NNS chamber will be iridium coated and then will be hot fire tested in the future for flight hardware certification, figure 22 . The time required to 
manufacture the TRW rhenium thruster was 12 weeks, but in the future 9 weeks should be possible. The Kaiser Marquardt chamber was the most difficult chamber to manufacture due to the large exit cone, figure 23. Several variations of mandrels, molds and can designs were used to produce the $490 \mathrm{~N}$ chamber. The $490 \mathrm{~N}$ would be made in a two-part component manufacturing process with a barrel section with a partial exit cone and a larger exit cone section. The exit cone section was produced either from a large ingot, figure 24 , or a NNS exit cone, figures 25 and 26 . An EB weld was required to assemble the two components together. The estimated time required to manufacture the Kaiser Marquardt $490 \mathrm{~N}$ chamber was 14 weeks.

After the completion of the 100lbf thrusters, a small $25 \mathrm{lbf}$ thruster was produced via near net shape manufacturing, figure 27 . The manufacturing time required for NNS $25 \mathrm{lbf}$ thruster was only 5 weeks.

\section{Conclusion}

Spin forming failed to produce acceptable NNS rhenium thrusters. However, advanced cold isostatic pressing techniques utilizing complex mandrels were very successful by delivering three different chambers to NASA Glenn Research Center/Small Business Innovation Research Office. The chambers had densities greater than $99.5 \%$ with fine grain microstructure. The quantity of rhenium metal powder used to produce a NNS rhenium chamber is reduced by approximately $70 \%$ versus the ingot process. The time needed for manufacturing was reduce by 30 to $40 \%$. The subsequent reduction in machining schedule and cost was reduced by nearly $50 \%$. The overall cost savings to a customer is 25 to $35 \%$. This innovation of near net shape processing will be an extremely important benefit when competing in the international market for satellite propulsion.

\section{References}

1. Chazen, M.L.. "Materials Property Test Results of Rhenium", AIAA Paper 95-2938, July 1995.

2. Chazen, M.L., and Sicher, D. " High Performance Bipropellant Engine", AlAA paper 98-3356, July 1998 .

3. Biaglow, J.A., "High Temperature Rhenium Materials Properties”, AlAA paper 98-3354. July 1998.

4. ASM Handbook Vol. 7, Powder Metal Technology and Applications, 1998.

5. Leonhardt, T.A., and Carlen, J.C., " Deformation Hardening and Process Annealing as Fundamental Elements in Rhenium Forming Technology", AIAA paper 98-3353, July 1998. 
Table 1: Hipped Rhenium mechanical properties.

\begin{tabular}{|c|c|c|c|c|c|c|c|}
\hline $\begin{array}{l}\text { SAMPLE } \\
\text { NUMBER }\end{array}$ & $\begin{array}{c}\text { TEST } \\
\text { TEMP (K) }\end{array}$ & $\begin{array}{c}\text { ANNEALING } \\
\text { TEMP (K) } \\
\text { TIME } \\
\end{array}$ & \begin{tabular}{|c|}
$0.2 \%$ \\
YIELD \\
STRENGTH \\
MPa \\
\end{tabular} & \begin{tabular}{|c|} 
ULTIMATE \\
STRENGTH \\
Mpa \\
\end{tabular} & \begin{tabular}{|} 
ELASTIC \\
MODULUS. \\
GPa
\end{tabular} & $\begin{array}{c}\text { \%STRAIN } \\
\text { TO } \\
\text { FAILURE } \\
\text { RATIO } \\
\end{array}$ & $\begin{array}{c}\% \\
\text { ELONGATION }\end{array}$ \\
\hline & & \multicolumn{3}{|c|}{$\begin{array}{l}\text { HOT ISOSTATIC PRESSED } \\
\text { PM RHENIUM } \\
\end{array}$} & & & \\
\hline HIPED-1 & 294 & $1922 / 0.5$ & 236.5 & 910.8 & 407.5 & 17.2 & \\
\hline HIPED-2 & 294 & $1922 / 0.5$ & 232.4 & 915.6 & 428.9 & 18.5 & \\
\hline HIPED-3 & 294 & $1922 / 0.5$ & 414.39 & 1017.8 & 301.86 & & 25 \\
\hline HIPED-4 & 294 & $1922 / 0.5$ & 422.87 & 1047.62 & 265.25 & & 30 \\
\hline HIPED-5 & 294 & $1922 / 0.5$ & 610.2 & 1067.6 & 311 & & 26 \\
\hline HIPED-6 & 294 & $1922 / 0.5$ & 506.8 & 997.6 & 479 & & 23.9 \\
\hline HIPED-7 & 1088 & $1922 / 0.5$ & 254.4 & 561.9 & 186.2 & 26 & \\
\hline HIPED-8 & 1088 & $1922 / 0.5$ & 264.1 & 497.8 & 193.7 & 12.3 & \\
\hline HIPED-9 & 1088 & $1922 / 0.5$ & 337.85 & 496.44 & 328.89 & & 14 \\
\hline HIPED-10 & 1088 & $1922 / 0.5$ & 375.85 & 552.28 & 326.13 & & 35 \\
\hline HIPED-11 & 1367 & $1922 / 0.5$ & 274 & 285.58 & 33.71 & & 7.2 \\
\hline HIPED-12 & 1367 & $1922 / 0.5$ & 264.5 & 271.03 & 30.46 & & 8.8 \\
\hline HIPED-13 & 1644 & $1922 / 0.5$ & 179.9 & 215.8 & 145.5 & 2.28 & \\
\hline HIPED-14 & 1644 & $1922 / 0.5$ & 191 & 251.6 & 137.2 & 4.49 & \\
\hline HIPED-15 & 1922 & $1922 / 0.5$ & 237.19 & 249.59 & 36.54 & & 14 \\
\hline HIPED-16 & 1922 & $1922 / 0.5$ & 175.13 & 198.57 & 59.29 & & 9 \\
\hline HIPED-17 & 2422 & $1922 / 0.5$ & 77.22 & 79.98 & 7.58 & & 10 \\
\hline HIPED-18 & 2422 & $1922 / 0.5$ & 77.22 & 83.43 & 10.34 & & 10 \\
\hline HIPED-20 & 2506 & $1922 / 0.5$ & 54.5 & 56.2 & 13.71 & & 19.2 \\
\hline
\end{tabular}




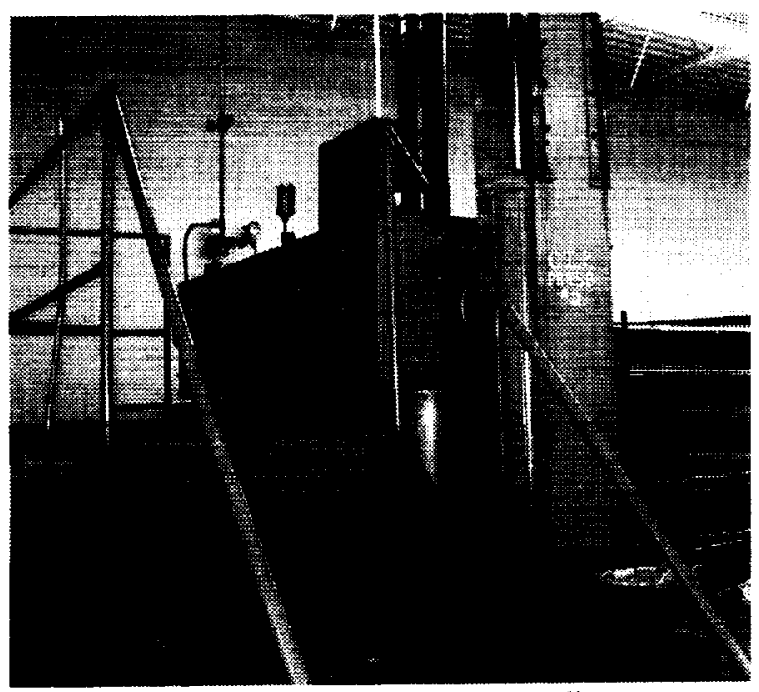

Figure 1: Cold lsostatic Press $203 \mathrm{~mm}$ diameter vessel rated at $410 \mathrm{MPa}$.



Figure 2: Ingots for the two-part construction of the TRW $440 \mathrm{~N}$ thruster.

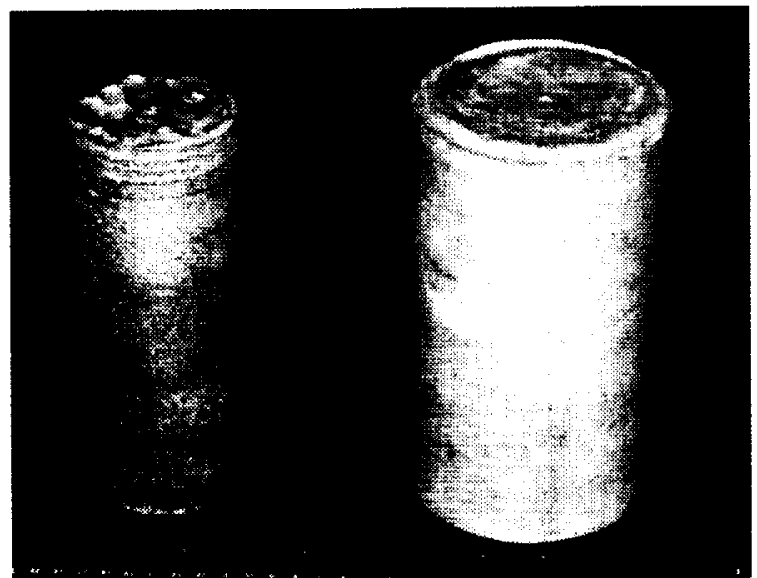

Figure 3: Ingots for the two-part construction of the Kaiser Marquardt $490 \mathrm{~N}$ thruster.

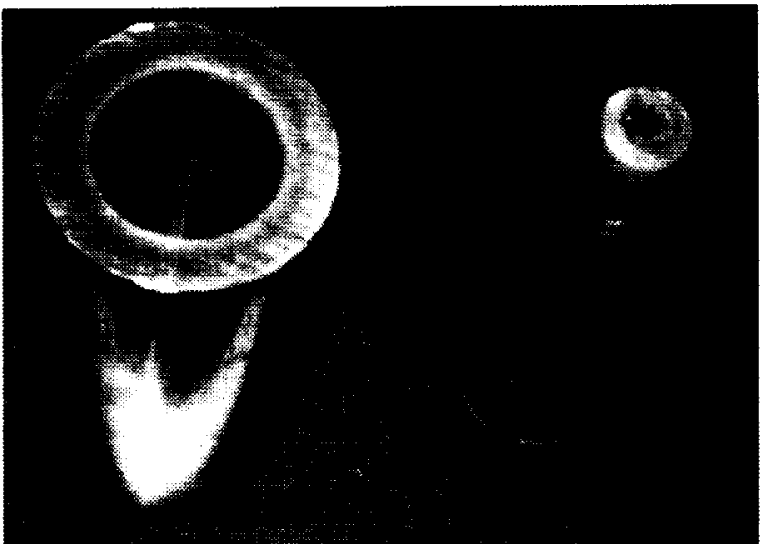

Figure 4: TRW barrel section ingot after wire EDMing the internal contours.

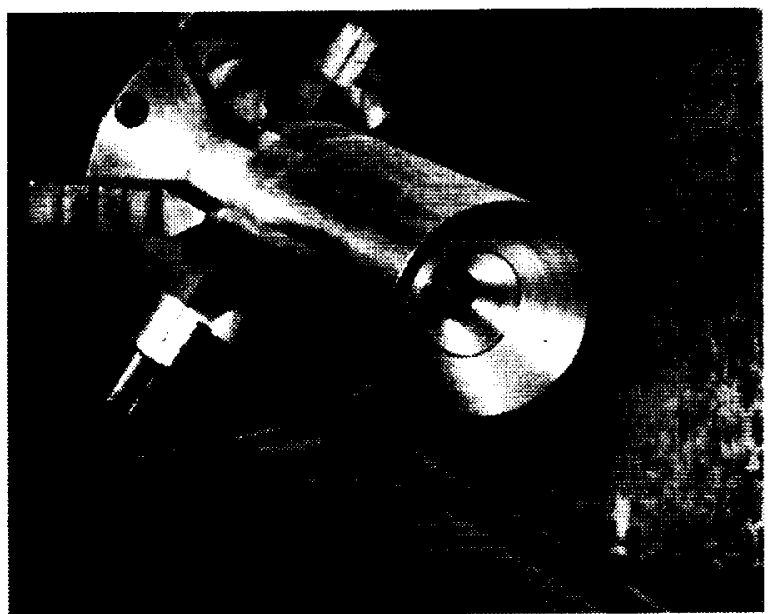

Figure 5: Diamond grinding of the internal contour.

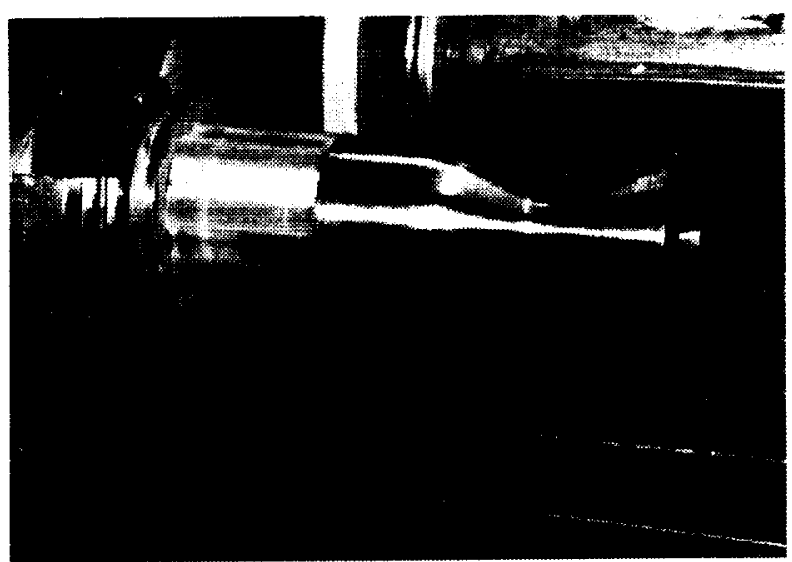

Figure 6: After EDMing off the excess rhenium from the outside diameter the thruster is diamond ground. 


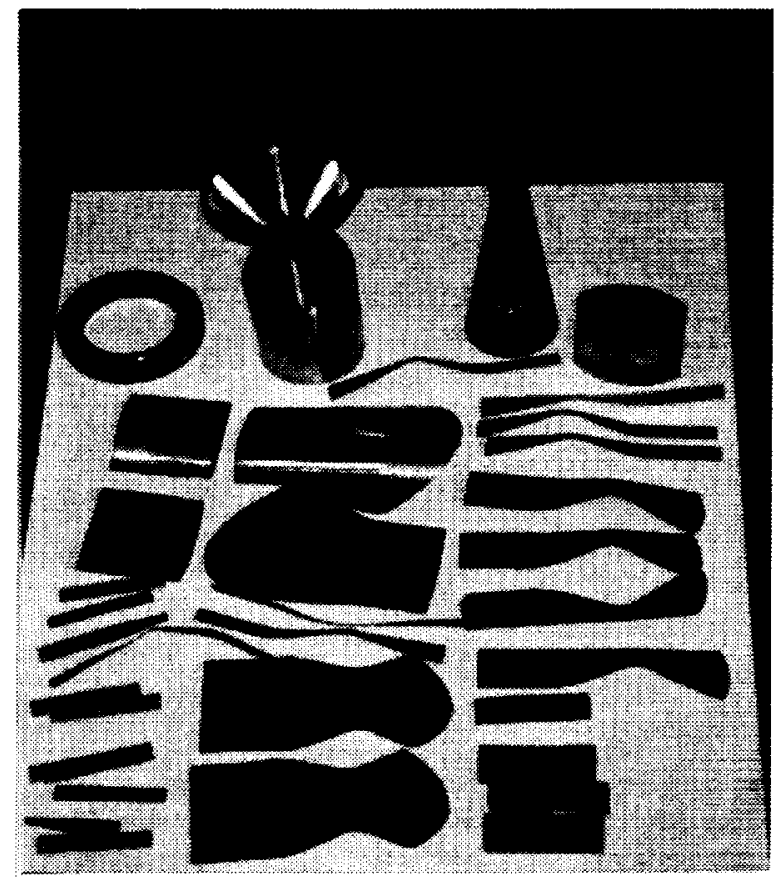

Figure 7: Ingot process produces over $20 \mathrm{Kg}$ of scrap rhenium.

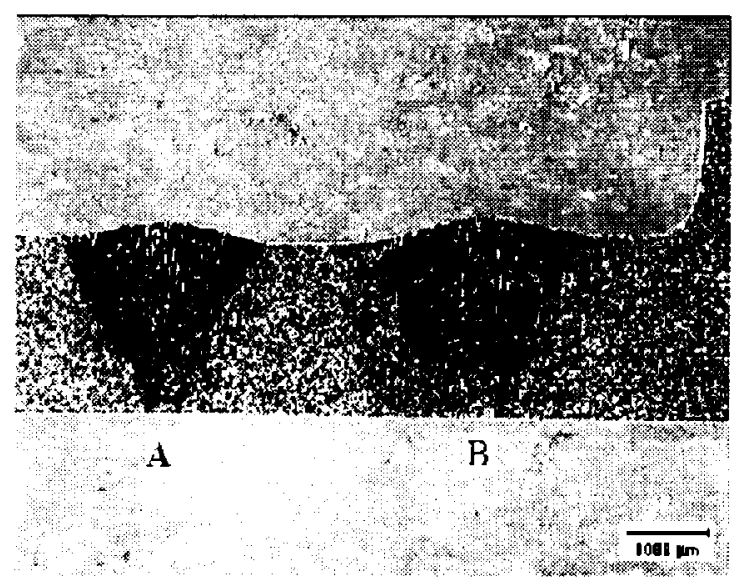

Figure 8: Electron beam welds show depth of penetration and width of heat affected area.

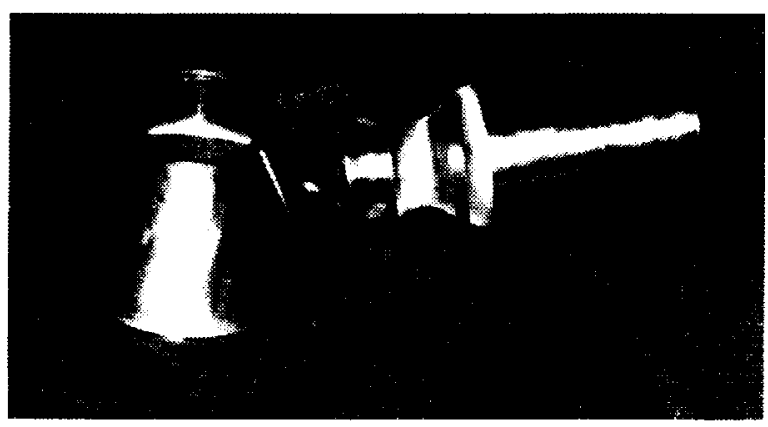

Figure 9: Barrel section and the exit cone for the Kaiser Marquardt thruster before electron beam welded together.

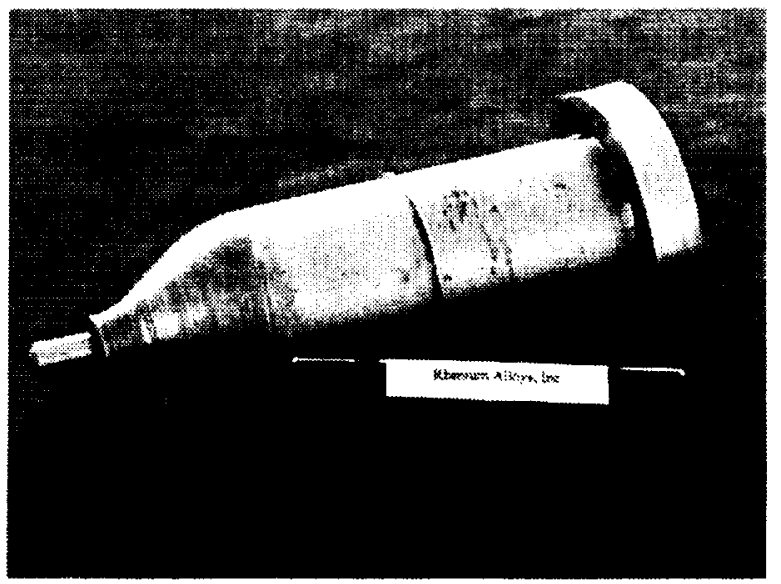

Figure 10: Internal mandrel for spin forming tubes. The contour has been machine into the tool to meet the desired dimensions of the thruster.

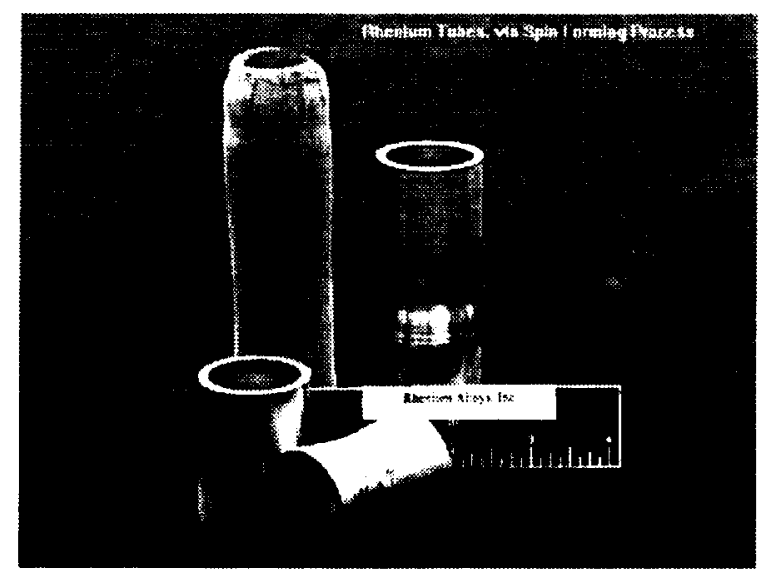

Figure 11: Spin formed small diameter tubes that have been spun down to different degrees of work and diameters.

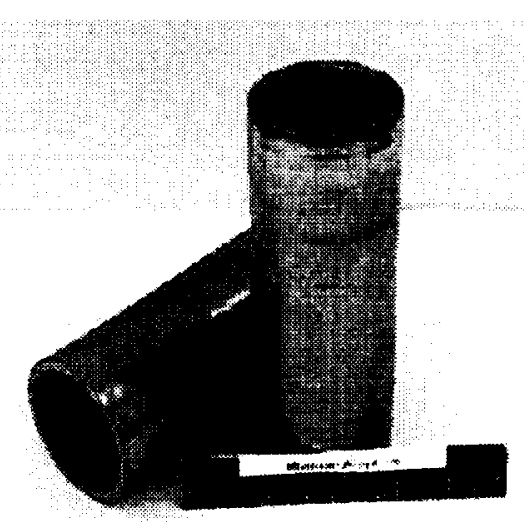

Figure 12: Hot isostatic pressed large diameter rhenium tubes. 


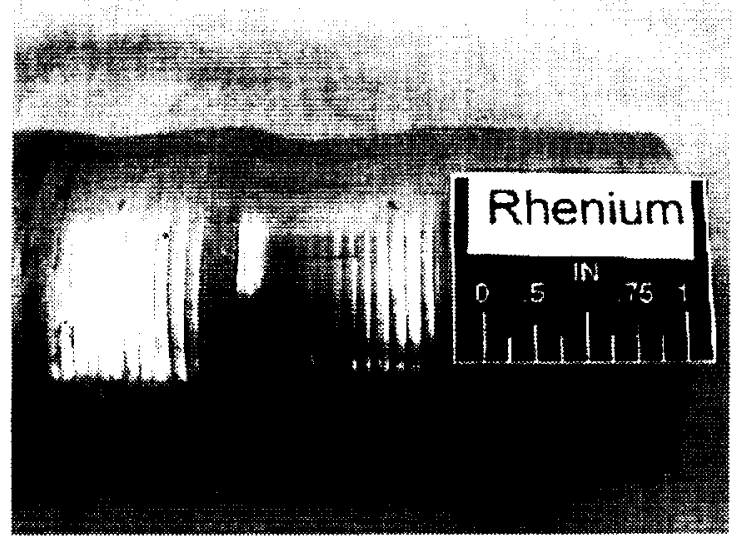

Figure 13: A tube showing spin forming passes to produce a concentric tube.

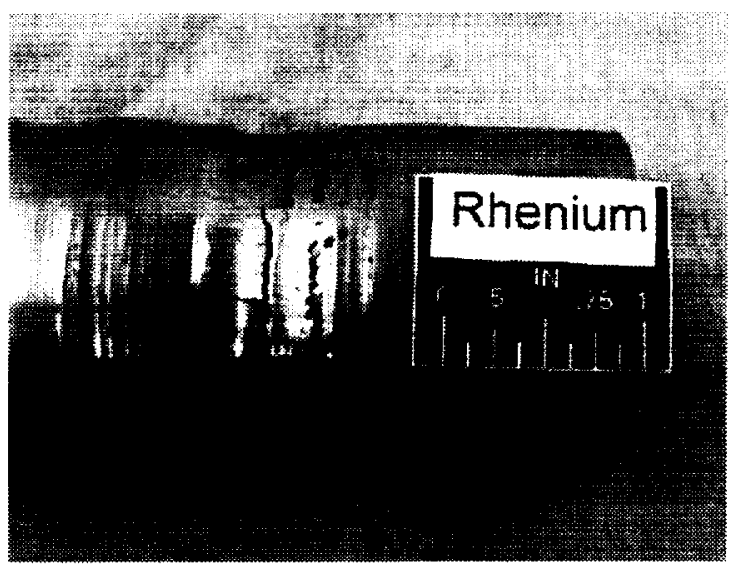

Figure 14: Over-worked spin formed rhenium tubes. The crack is circumferential with small radial cracks.

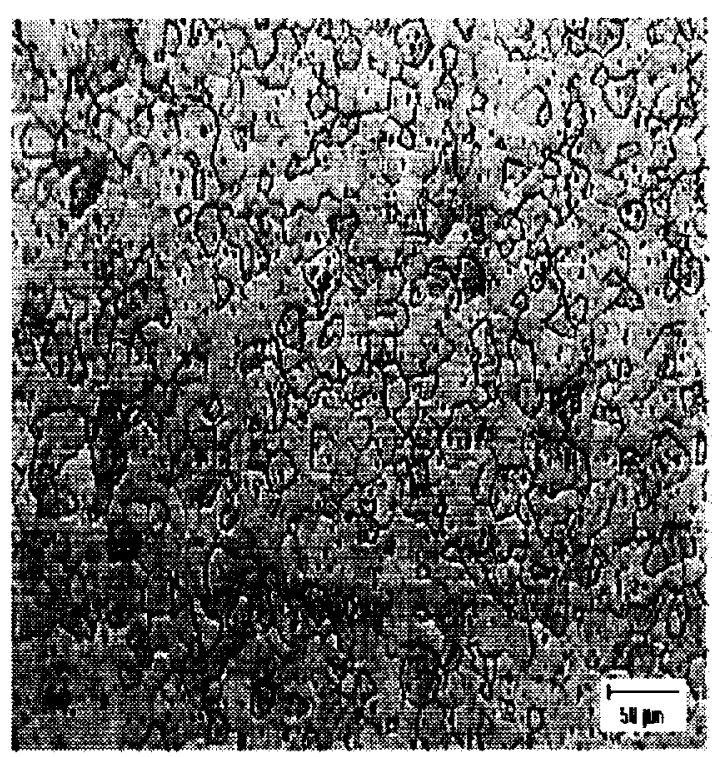

Figure 15: A fine grain microstructure near the outside diameter.

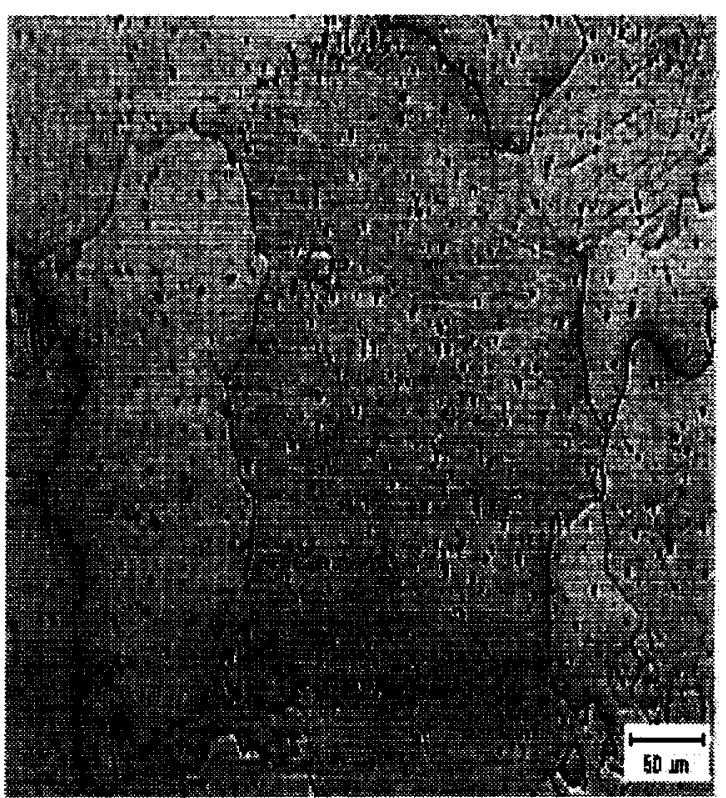

Figure 16: The microstructure between the outside and inside diameters of the tube shows large grains and less dense material.

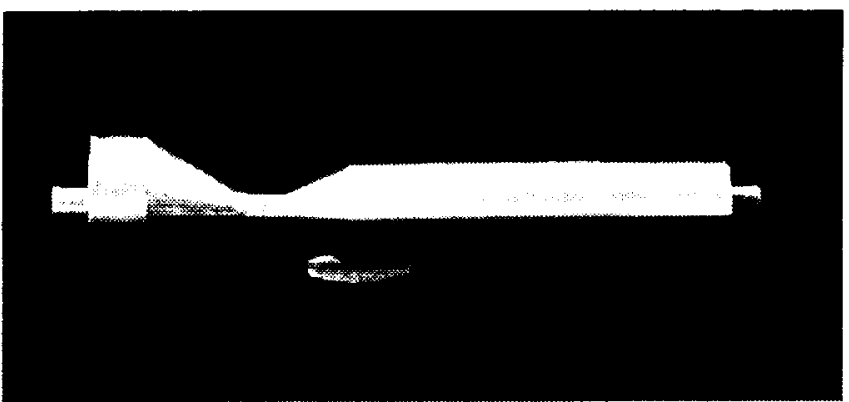

Figure 17: Two-part mandrel for the $100 \mathrm{lbf}$ thrusters.

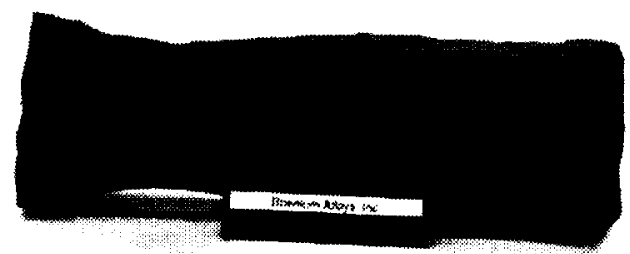

Figure 18: The TRW 440N rhenium thruster compact after pressing with the complex mandrel removed. 


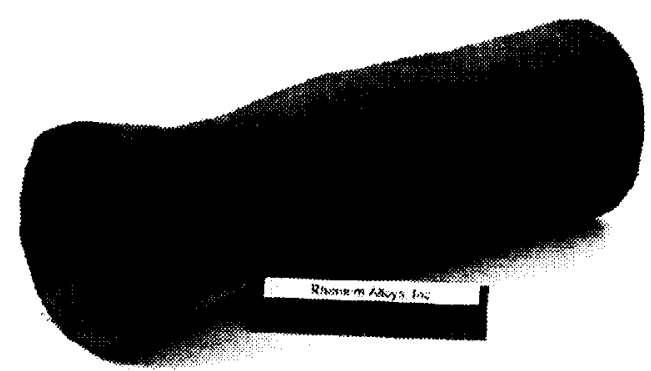

Figure 19: The TRW 440N rhenium thruster after pre-sintering.

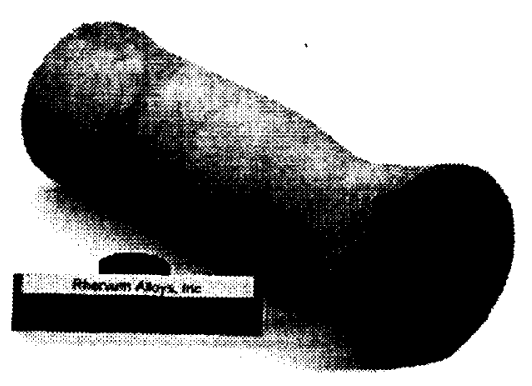

Figure 20: The NNS TRW $440 \mathrm{~N}$ thruster after sintering has a density greater than $97 \%$.

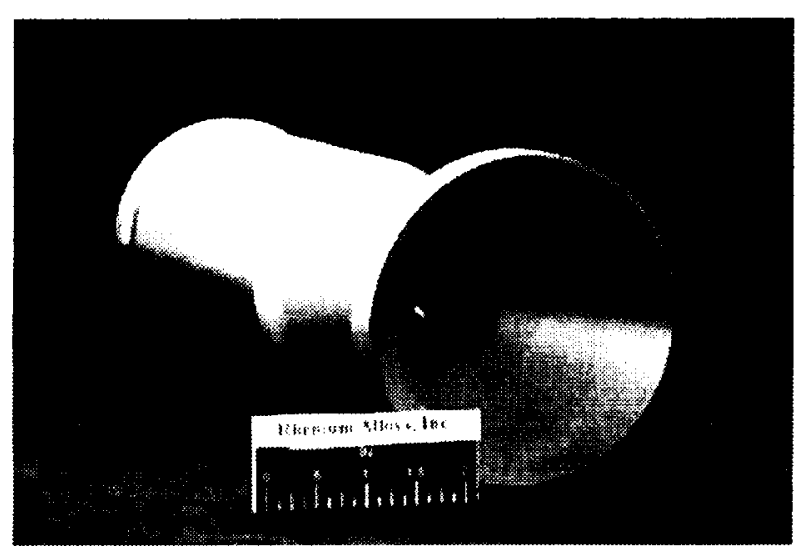

Figure 21: The NNS TRW $440 \mathrm{~N}$ thruster after machining and cleaning.

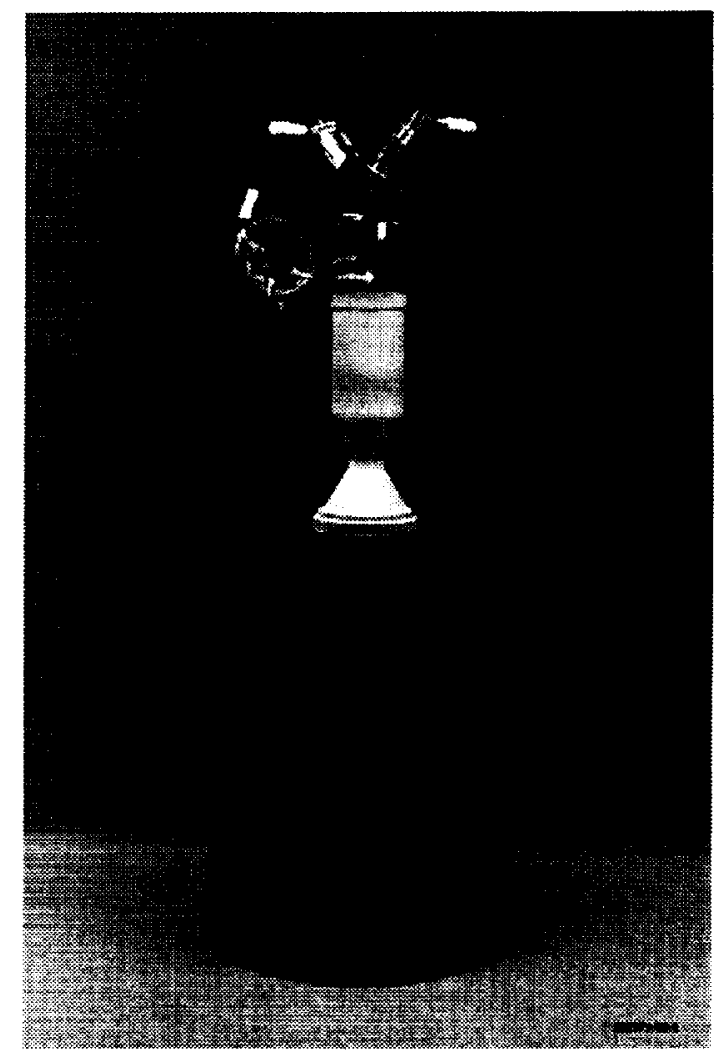

Figure 22: TRW Liquid Apogee Engine - TR312$100 \mathrm{MN}$.

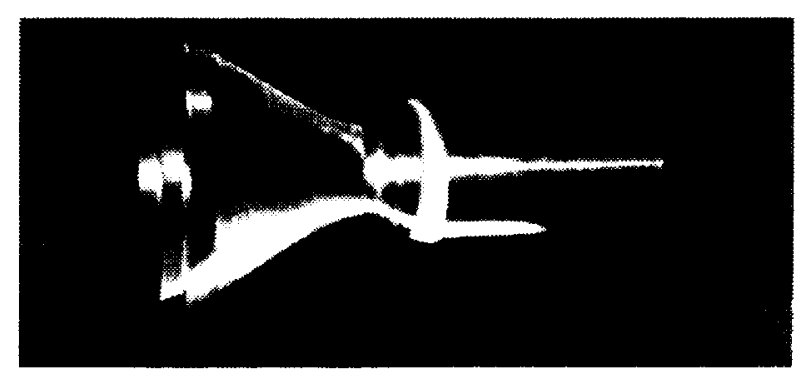

Figure 23: The NNS Kaiser Marquardt 490N thruster after machining and cleaning. 


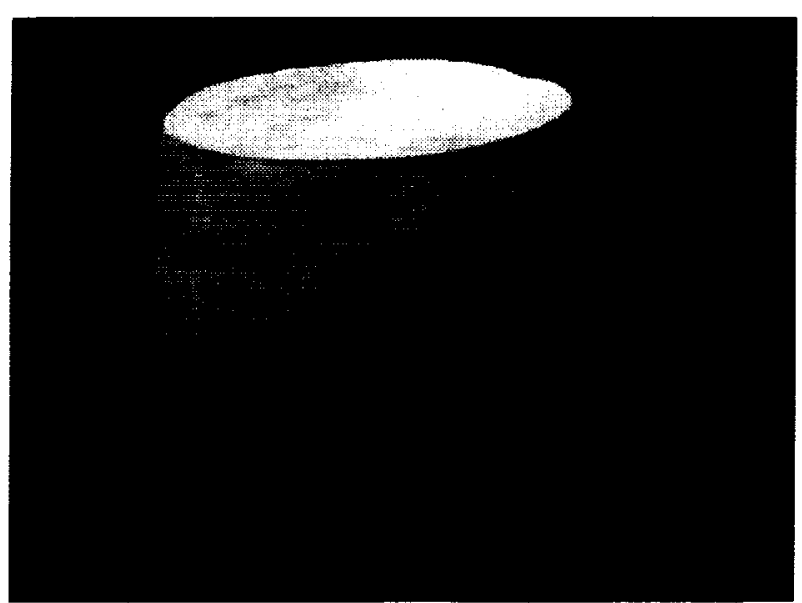

Figure 24: $25 \mathrm{Kg}$ Rhenium ingot for the Kaiser Marquardt $490 \mathrm{~N}$ thruster exit cone. The ingot measured $127 \mathrm{~mm}$ diameter by $127 \mathrm{~mm}$ high.

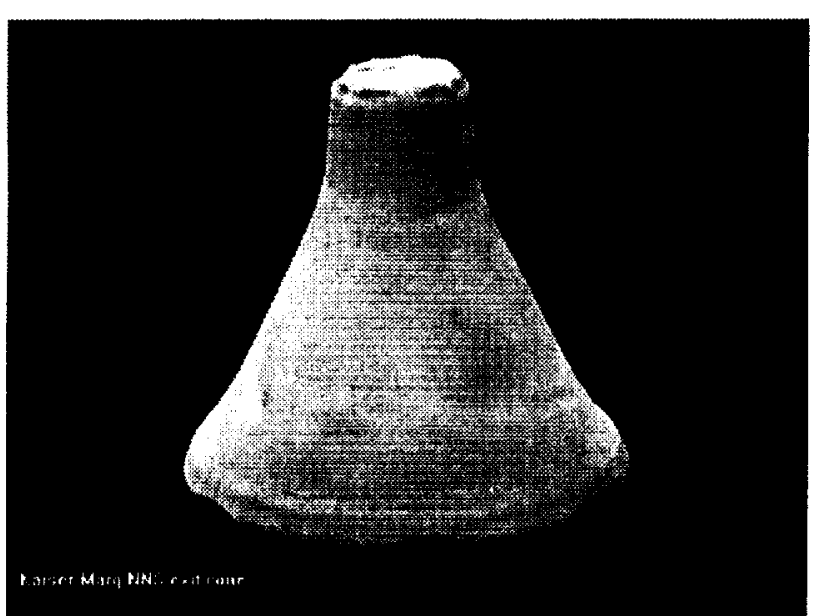

Figure 25: NNS Kaiser Marquardt exit cone The NNS exit cone weights $4.7 \mathrm{Kg}$.

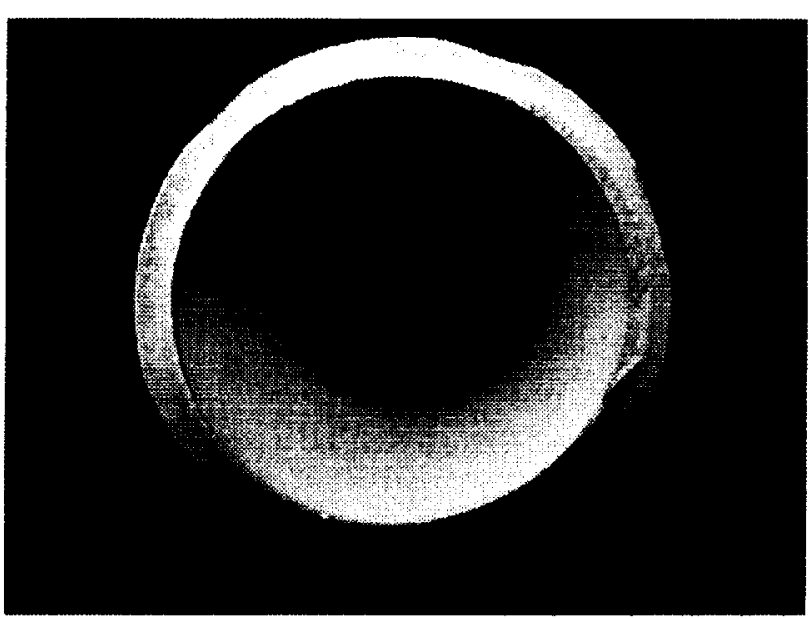

Figure 26: The cone shaped NNS Kaiser Marquardt exit cone.

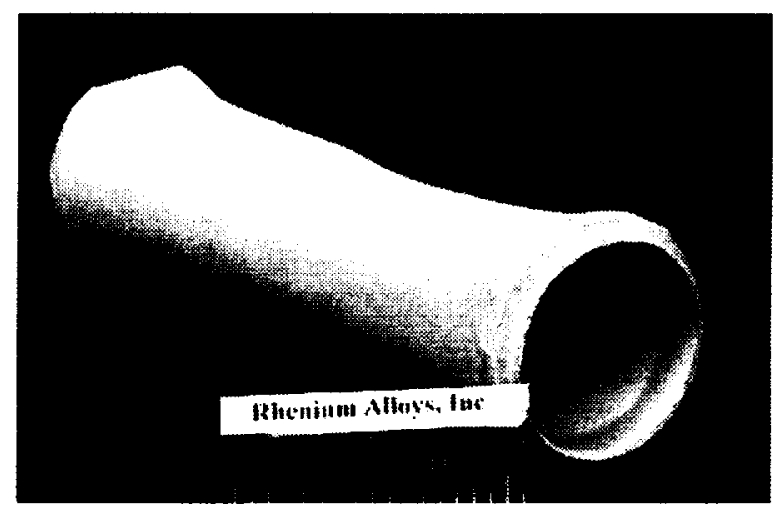

Figure 27: NNS 25-pound force thruster before machining. 

